\title{
Fabrincando: as oficinas do jogo como proposta educacional nas séries iniciais do ensino fundamental
}

\author{
João Batista Freire* \\ Ciro Goda**
}

\begin{abstract}
Resumo: Considerando as dificuldades históricas das crianças brasileiras freqüentadoras de escolas públicas para aprender os conteúdos básicos, sugerimos uma prática pedagógica com maior poder de melhorar a qualidade dessa aprendizagem. Partindo da idéia de que o lúdico constitui ambiente favorável à aprendizagem, o objetivo central deste estudo foi verificar o potencial das Oficinas do Jogo como prática pedagógica capaz de produzir repercussões nas demais aprendizagens escolares, bem como produzir aprendizagens em outros planos não previstos pela escola tradicional. As Oficinas do Jogo são uma prática pedagógica localizada na disciplina Educação Física, na qual as crianças, jogando, aprendem as bases do conhecimento (pensamento, motricidade, sociabilidade, moralidade, afetividade, etc.), e o fazem de modo a repercutir em outras disciplinas escolares. O método de investigação adotado foi o da Pesquisa-Ação.
\end{abstract}

Palavras-Chave: Educação Física. Jogos e brinquedos. Ensino Fundamental e médio. Pedagogia.

\section{INTRODUÇÃO}

Nunca tantas crianças estiveram matriculadas nas escolas brasileiras; apesar disso, suas dificuldades para aprender os conteúdos escolares continuam, em boa parte das escolas brasileiras, insuperáveis. O Sistema Nacional de Avaliação da Educação Básica (SAEB, 2003) revelou um triste quadro: para um percentual

\footnotetext{
*Professor Doutor dos Programas de Graduação e Pós-graduação da Universidade Estadual de Santa Catarina (UDESC). Coordenador do Grupo de Estudos Oficinas do Jogo. Florianópolis, SC, Brasil. E-mail: mrfreire32@terra.com.br

" Professor da Escola Educação Básica Hilda Teodoro Vieira. Membro do Grupo de Estudos Oficinas do Jogo. Florianópolis, SC, Brasil. E-mail:, cirogohda@yahoo.com.br
} 
significativo de nossas crianças com quatro anos de escolarização, ler e escrever são tarefas consideradas das mais difíceis. Neira e Nunes (2006), em obra recentemente publicada, lembram que, “[...] em cada época, o currículo configurou-se como um espaço singular, onde setores privilegiados da sociedade imprimiram sua marca, formatando homens e mulheres para servirem e perpetuarem seus interesses". (NEIRA; NUNES, 2006, p. 105). Entende-se, portanto, por que os mais atingidos pela não aprendizagem cursam escolas que atendem comunidades economicamente empobrecidas. Daí a importância, para os grupos que se perpetuam no poder, de impedir um currículo que seja feito a partir dos alunos e dos professores, isto é, a partir dos oprimidos, na visão de Paulo Freire (2005a), ou das vítimas, segundo o dizer de Henrique Dussel (2000). A lucidez do Prof. Manuel Sérgio (2005) resume esse problema: "Pensar o novo, investigar o diferente, aprender a aprender - são comportamentos que o Poder detesta e os seus esbirros de esquina ou de gabinete impedem, tanto pela "lei da força", como pela 'força da lei .” (SÉRGIO, 2005, p. 52).

A Educação Física é uma prática secular, portadora de forte carga cultural. Segundo Soares, et al. (1993, p.61), "A Educação Física é uma disciplina que trata, pedagogicamente, na escola, do conhecimento de uma área denominada aqui de cultura corporal", configurada, conforme a proposta curricular para o Estado de Santa Catarina (SANTA..., 1998, p.153), de modo "[...] que dentro de qualquer processo educacional ela possa ser percebida como um componente curricular nem mais nem menos importante que os demais, e que busque, junto com eles, fazer com que os objetivos educacionais sejam alcançados".

No compromisso de reestruturação do conhecimento, e no desafio de romper a secular dificuldade de aprendizagem e o desinteresse gradativo da criança (que anseia pelo primeiro dia de aula, mas logo se desencanta) é que são inseridos, em nosso programa pedagógico denominado Ofícinas do Jogo, outros fundamentos, como o estético e o lúdico, que não somente aqueles referendados pela tradição educacional.

Movimento, Porto Alegre, v. 14, n. 01, p. 111-134, janeiro/abril de 2008. 
Essas oficinas prevêem como materiais didáticos, objetos feitos de material reciclável, transformados em peças que servem a inúmeros jogos. O universo didático rico, bonito, diversificado, aumenta as possibilidades de formação dos conhecimentos de base (aprender a pensar, aprender a fazer, aprender a se relacionar, aprender a lidar com os sentimentos, aprender a construir regras, aprender a aprender, aprender a viver).

A beleza do cenário de aula proporcionada pelo material didático elaborado especificamente para as Oficinas do Jogo encanta as crianças, chama sua atenção, resolvendo um grave problema escolar: a falta de atenção dos alunos durante as aulas. O jogo, de sua parte, constitui o motor das aulas, a motivação principal das crianças. Entendemos jogo como aquela atividade que, entre os humanos, é realizada quando necessidades básicas não precisam ser satisfeitas. Quando a criança não tem fome, brinca de comer, quando não tem sono, brinca de dormir, por exemplo. Arnold Gehlen (1987) dizia que:

Apesar de ser impossível estabelecer uma medida, pode supor-se, em uma primeira aproximação deste difícil problema, que a energia pulsional em potência, puramente quantitativa, considerada desde o ponto de vista energético, é maior no homem que em qualquer outro animal de seu tamanho (GEHLEN, 1987. p. 65).

Henri Atlan, comentando Winnicot, escreve algo bastante semelhante ao que escreveu Gehlen. Ele fala do jogo:

\begin{abstract}
Este espaço potencial é, efectivamente, descrito como "lugar do jogo e da experiência cultural" sob todos os aspectos. A cultura, como "extensão da idéia de fenômenos transicionais", e que designa "aquilo em que ocupamos a maior parte do nosso tempo quando temos prazer naquilo que fazemos", teria, assim, uma existência que não está nem no indivíduo nem à sua volta, no mundo da realidade partilhada. (ATLAN, 1994, p. 236).
\end{abstract}

No campo da Educação Física, as dúvidas e equívocos a respeito do conceito de jogo, são bastante generalizados. Alguns designam certas atividades lúdicas como brincadeiras, outros como

Movimento, Porto Alegre, v. 14, n. 01, p. 111-134, janeiro/abril de 2008. 
jogo, outros ainda como esporte. Tentamos dar um pouco de clareza a esse quadro informando que jogo é o fenômeno que manifesta uma das dimensões do ser humano: sua dimensão lúdica. Quando joga, o homem realiza atividades que não estão vinculadas a compromissos objetivos, isto é, ele não joga para cumprir obrigações, e nem se importa em antecipar os resultados. Em certas circunstâncias, o jogo manifesta-se como brincadeira (em crianças, adolescentes ou adultos). Trata-se de um jogo menos regrado socialmente, mais circunscrito a pequenos grupos. Noutras circunstâncias, o jogo manifesta-se como esporte, quando as regras são suficientes para integrar um grupo populacional grande, chegando a ser universal. Há os casos em que o jogo manifesta-se como lutas, como danças, como festas, e até como conversas desinteressadas entre pessoas ou simples jogos de imaginação individual.

Piaget (1978, p. 188), na sua lucidez, realiza críticas ao modo como os autores, de modo geral, procuram compreender o jogo: "[...] o grande número das teorias explicativas do jogo desenvolvidas até aqui mostra suficientemente que esse fenômeno resiste à compreensão causal. Mas a razão dessa resistência é talvez que se tende a fazer do jogo uma função isolada."

Encerramos essa complexa questão sobre a compreensão do fenômeno jogo, transcrevendo um dos comentários de Freire, J. B.:

Resta, portanto, buscar o significado do jogo, não mais na caracterização infindável de partes que o compõem, mas sim na identificação dos contextos em que ocorre. Seguramente há um nicho ecológico que acolhe o jogo e lhe permite manifestar-se, o único ao qual ele se adapta. É nesse ambiente que temos de penetrar para tentar compreender o fenômeno do jogo (FREIRE, 2002, p. 58).

Rompendo com a tradicional aula de Educação Física, este estudo tem a intenção de verificar como se desenvolvem as crianças em vários planos educacionais, e não só no lógico-matemático (preocupação quase exclusiva do projeto escolar tradicional, exceto pela preocupação moral, uma moral conservadora, velada, mas presente nos planos educacionais). Interpondo-se entre a Educação

Movimento, Porto Alegre, v. 14, n. 01, p. 111-134, janeiro/abril de 2008. 
Física e outras áreas (como as disciplinas de português, matemática e artes), através da indagação, da troca de idéias, do observar, agir e construir, o lúdico, da maneira como é praticado nas Oficinas do Jogo, permite que os alunos exercitem valores e habilidades decisivas como instrumentos de emancipação, tais como a estética, o respeito, a justiça, a solidariedade, a motricidade, confiança e cooperação, entre outros, a partir das ações desenvolvidas nas aulas.

Para Freire, (1989, p.182-3),

Seria necessário descaracterizar o valor utilitário da Educação Física. Esta não pode justificar sua existência com base na possibilidade de auxiliar o aprendizado dos conteúdos de outras matérias quem faz Educação Física aprende Matemática com maior facilidade. Até seria desejável que assim fosse, mas que não seja por essa finalidade que a Educação Física se faça presente na escola. Pelo contrário, mesmo considerando-se a interdisciplinaridade um componente indispensável ao ensino, a Educação Física deve se justificar por si mesma, pelo conteúdo que desenvolve na escola.

Uma escola democrática é, como salienta Freire, P. (2005b p. 6):

Uma escola que, continuando a ser um tempoespaço de produção de conhecimento em que se ensina e em que se aprende, compreende, contudo, ensinar e aprender de forma diferente. Em que ensinar já não pode ser este esforço de transmissão do chamado saber acumulado, que faz uma geração à outra, e aprender não é a pura recepção do objeto ou do conteúdo transferido.

Pelo contrário, trata-se de um espaço que se constrói em torno da compreensão do mundo e, como finaliza o autor (FREIRE, P., 2005b, p.6), “[...] dos objetos, da criação, da boniteza, da exatidão científica, do senso comum, ensinar e aprender giram também em torno da produção daquela compreensão, tão social quanto a produção da linguagem, que é também conhecimento."

Piaget (1979) mostra, do ponto de vista psicológico, a importância da ação do sujeito sobre o meio no processo de aprendizagem.

Movimento, Porto Alegre, v. 14, n. 01, p. 111-134, janeiro/abril de 2008. 
O que se vê na escola, contudo, com freqüência preocupante, é a prática de uma ação pedagógica do imobilizar-se e do silêncio sepulcral.

Quando da realização de sua dissertação de Mestrado, Feijó (2005) mostrou a eficácia que uma pedagogia como a praticada nas Oficinas do Jogo pode ter ao ser aplicada na educação de crianças. A pesquisadora recorreu a aulas em que temas eram sugeridos para o trabalho com as crianças. No caso desta pesquisa, os temas não eram sugeridos pelos professores, mas sim, definidos pelos próprios alunos.

\section{0bJetivo}

Considerando as dificuldades históricas das crianças brasileiras freqüentadoras de escolas públicas para aprender os conteúdos básicos, supomos ser possível experimentar uma prática pedagógica com maior poder de melhorar a qualidade dessa aprendizagem. Partindo da idéia de que o lúdico constitui ambiente favorável à aprendizagem, quando lidamos com crianças, o objetivo central deste estudo é avaliar o potencial das Oficinas do Jogo como prática pedagógica capaz de produzir repercussões nas demais aprendizagens escolares, bem como produzir aprendizagens em outros planos não previstos pela escola tradicional, a partir de temas de aulas gerados pelos próprios alunos.

\section{Metodologia}

\subsection{O método de pesquisa}

Nesta pesquisa, julgamos que a Pesquisa-Ação é a que melhor serve ao pesquisador, pois se trata de estudar um problema em sua dinâmica. Quisemos nos colocar, como investigadores, no meio da cena educacional, vivendo-a, tanto como professores e alunos, quanto como investigadores. O que apresentaremos aqui é essa possibilidade

Movimento, Porto Alegre, v. 14, n. 01, p. 111-134, janeiro/abril de 2008. 
de educar pesquisando, de aprender ensinando. Que não se entenda, porém, que esquecemos tratar-se, a ciência, de uma interpretação dos fatos. A lição de Ortega y Gasset (1989 p. 26) ficou: "Para descobrir a realidade é preciso que retiremos por um momento os fatos de em torno a nós e fiquemos a sós com nossa mente". Esta Pesquisa-Ação foi realizada por dois investigadores, sendo um deles o próprio professor que ministrava as aulas pesquisadas. Tais aulas eram norteadas por princípios pedagógicos e procedimentos produzidos pelo projeto Oficinas do Jogo. A maneira como essas aulas se desenrolavam, e que conhecimentos as crianças construíam nas relações geradas, era o objeto maior das investigações.

Ser uma pesquisa pedagógica, como se define a Pesquisa-Ação, cria uma harmonia mais estreita entre a investigação e a cena educacional. Franco (2006) a define assim:

Quero com isso esclarecer que a pesquisa-ação, estruturada dentro de seus princípios geradores, é uma pesquisa eminentemente pedagógica, dentro da perspectiva de ser o exercício pedagógico, configurado como uma ação que cientificiza a prática educativa, a partir de princípios éticos que visualizam a contínua formação e emancipação de todos os sujeitos da prática. (FRANCO, 2006, p.6).

Um diário de campo, fácil de transportar, sempre à mão para serem efetuados registros, foi imprescindível. Nesse diário, o desenrolar de cada aula era sempre anotado e confrontado com o plano que a antecedia. Além disso, como era necessário investigar a respeito do conhecimento construído durante as aulas, observávamos o comportamento dos alunos, anotando suas falas (entre alunos e alunos com professores), vários de seus gestos, e a realização dos jogos (as particularidades de cada construção nos jogos).

O diário não é o único instrumento importante para uma Pesquisa-Ação. Há outros, igualmente importantes. Neste estudo optamos, após um longo período de aulas, por pedir aos alunos que escrevessem em uma folha, a respeito de uma questão central: $\mathrm{O}$ que vocês aprenderam nas Oficinas do Jogo? É interessante ressaltar

Movimento, Porto Alegre, v. 14, n. 01, p. 111-134, janeiro/abril de 2008. 
que várias das crianças não sabiam ler ou escrever quando nossas aulas começaram.

Alguns pesquisadores da área da Educação Física têm recorrido à Pesquisa-Ação, considerando ser uma modalidade bastante pertinente quando se trata de ações pedagógicas.

A pesquisa-ação foi o método principal utilizado na investigação, envolvendo as teorias e as ações docentes, assim como as transformações eventuais na prática cotidiana. Este método derivado da etnografia no contexto educacional é o mais indicado nos casos em que o professor é o próprio pesquisador. Neste trabalho, os próprios autores pesquisaram sua prática no dia-a-dia, encontrando-se sistematicamente para refletir e planejar coletivamente sua intervenção. (NETO et al, 2006, p. 1)

Betti, pesquisando as relações da escola com a mídia eletrônica, também recorreu aos procedimentos da Pesquisa-Ação, enfatizando seu caráter pedagógico:

Mas não se tratou de um "programa de treinamento", no qual se diria aos professores/as o que fazer e como fazer. Ao contrário, considerou-se o pressuposto de que os/as professores/as têm algo a dizer sobre o que fazer e como fazê-lo, implicando na necessidade de diálogo de caráter construtivo, num trabalho de parceria em que, como decorrência das experimentações e debates, todos os interlocutores buscaram conjuntamente as "soluções", e assim aumentaram seus conhecimentos sobre a adequação de estratégias/conteúdos no uso de matérias televisivas em aulas de Educação Física. (BETTI, 2006, p. 102).

Encerramos este tópico com as palavras, já tão conhecidas, de Thiollent (2004, p. 14):

Pesquisa-ação é um tipo de pesquisa social com base empírica que é concebida e realizada em estreita associação com uma ação ou com a resolução de um problema coletivo e no qual os pesquisadores

Movimento, Porto Alegre, v. 14, n. 01, p. 111-134, janeiro/abril de 2008. 
e os participantes representativos da situação ou de problema estão envolvidos de modo cooperativo ou participativo.

\subsection{O local de realização da pesquisa}

A pesquisa foi realizada em uma Escola de Educação Básica pertencente à Rede Estadual de Ensino no Município de Florianópolis, SC. A configuração física das moradias, em certo sentido, identifica os segmentos sociais existentes na região: da rua principal do bairro até à metade do morro, onde ainda há asfalto, casas de classe média alta; daí por diante, subindo o morro, um núcleo habitacional composto de, na sua maioria, migrantes do interior do Estado. Nossos alunos provinham desse segundo segmento.

\subsection{Os alunos que participaram da pesquisa}

Os alunos que integraram este estudo pertencem a este segundo núcleo, todos de família de baixa renda. Selecionamos duas turmas, uma no matutino, composta de dez meninos e doze meninas, e outra no período vespertino, com dez meninos e catorze meninas. Portanto, fizemos este trabalho com quarenta e seis alunos no total, com idades entre sete e oito anos, da segunda série do Ensino Fundamental.

\subsection{As Oficinas do Jogo}

Não há, nas Oficinas, a simetria pretendida pelo espaço arquitetado em sala de aula. As Oficinas do Jogo, portanto, iniciam por romper com essa arquitetura, para depois, romper com a tradição curricular. As Oficinas do Jogo pretendem cobrir outros campos do conhecimento humano, igualmente importantes, tais como as relações sociais, o campo moral, a motricidade, a afetividade, a sensibilidade e a estética. As Oficinas do Jogo supõem espaços de movimentação livre, ambientação lúdica, cenários coloridos e diversificados. No entanto, as Oficinas do Jogo não pretendem ser uma pedagogia à parte da escola; pelo contrário, a idéia é funcionar onde funciona a escola tradicional. As Oficinas do Jogo não se propõem combater a escola tradicional, mas atuar onde ela atua.

Movimento, Porto Alegre, v. 14, n. 01, p. 111-134, janeiro/abril de 2008. 
No início dos trabalhos, procuramos a direção da escola para apresentar o plano pedagógico das Oficinas do Jogo e solicitar autorização para aplicá-lo em duas turmas de alunos. Após a autorização, foi a vez de conversar com os demais professores, mesmo os que não se envolveriam com as turmas em questão. ${ }^{1}$ Em seguida, o professor da turma de alunos, que era um dos pesquisadores, conversou com as crianças sobre o que se pretendia fazer nas próximas aulas, que eram as aulas reservadas à disciplina Educação Física.

Durante um mês, no início do segundo semestre de 2004, as crianças e seus pais arrecadaram materiais recicláveis para confecção do material didático. Em seguida, providenciamos um mutirão, no qual participaram alunos, pais de alunos e professores. Nesse mutirão construímos o material necessário às aulas; as peças foram pintadas com tinta brilhante, em quatro cores. A diversidade do material, além das cores, dava-se também quanto aos pesos, formas, tamanhos e texturas.

Tratando-se de uma primeira série do Ensino Fundamental, julgamos mais apropriados para as crianças os jogos de faz-deconta ou simbólicos, os jogos de construção, e os jogos sociais. Os materiais construídos durante o mutirão poderiam ser utilizados em quaisquer jogos, porém, mais especialmente, nos jogos simbólicos e de construção.

Tínhamos experiência, em trabalhos anteriores (FEIJÓ, 2005), de realizar aulas com temas sugeridos pelos/as professores/as. Neste caso, queríamos ver os efeitos do trabalho após desenvolver temas sugeridos pelas próprias crianças.

No início de cada aula o professor da turma reunia os alunos em roda, sentavam-se no chão e conversavam sobre a aula anterior e o que deveriam fazer na aula daquele dia. Durante as primeiras aulas, os alunos manifestaram interesse por brincar com os materiais, porém, alterando a cada instante os temas. Eram livres para decidir do que brincar. Fizeram construções representando suas casas,

${ }^{1}$ Pesquisa autorizada pelo Comitê de Ética da UDESC: Universidade do Estado de Santa Catarina.

Movimento, Porto Alegre, v. 14, n. 01, p. 111-134, janeiro/abril de 2008. 
coisas do seu bairro, histórias, mas não se fixando em nenhum dos temas. Até que, várias aulas depois de iniciado o semestre letivo, os alunos começaram, utilizando o material didático, a construir o que representava, para eles, um supermercado.

A partir da definição do tema Supermercado, os alunos não quiseram mais mudá-lo. Mantiveram-se até o final do ano letivo brincando com esse tema.

Os materiais destinam-se, segundo Freire e Scaglia (2003, p. 62) “[...] particularmente - mas não exclusivamente - ao tema Jogos de Construção e às atividades a ele relacionadas, uma categoria de jogos que auxiliam na transição entre a atividade egocêntrica da criança e a atividade descentrada, socializada."

No início de cada aula as crianças conversavam com o professor/pesquisador a respeito do supermercado. Acrescentavam, a cada aula, novos elementos. Chegamos ao final do ano com um estabelecimento completo: prateleiras, mercadorias, caixas, sistema de administração, controle econômico.

\section{A Interpretação dos Dados Obtidos e a Transformação DA REALIDADE}

\subsection{Vejamos algumas cenas referentes à moralidade.}

Uma menina dirige-se ao professor: “- Eu não vou brincar com A. Ela não sabe brincar. Todo brinquedo é dela, não empresta para a gente. Só ela quer mandar. E não obedece também.”

Trata-se de uma situação típica de moralidade. A criança sentese injustiçada. Recorre ao professor para que ele intermedie a situação e faça justiça. A não sabia compartilhar o brinquedo. Os jogos de faz-de-conta cumprem a função de ajudar a criança na transição entre um estado bastante autocentrado e um estado heterocentrado.

Movimento, Porto Alegre, v. 14, n. 01, p. 111-134, janeiro/abril de 2008. 
Diversas aulas adiante nota-se o progresso nas relações: "B: Você não está vendo que o que você pegou é o pneu do meu carrinho? C: - Eu só estou vendo, calma! Sou sua amiga! B: - C, olhe com os olhos, não com as mãos. E complementa: - tá bom."

Numa outra aula, as relações mais equilibradas ainda, uma das crianças avisa: "- O supermercado está aberto, organizem-se e podem entrar. Boas compras!"

Nesse ponto, a diretora da escola, observando a brincadeira das crianças, comenta: "Eles se comportam como se fossem adultos, levam a sério a brincadeira, não vejo ninguém agredindo, empurrando ou mesmo discutindo."

Do ponto de vista da moralidade, houve significativo avanço no conhecimento das crianças. Não é de estranhar: por um lado, a idade delas favorecia tal transformação. Por outro, o envolvimento em jogos coletivos, que não podem ser realizados a não ser chegandose a acordos sociais.

\subsection{Progressos referentes à motricidade (dimensão em que se ancora a disciplina Educação Física).}

As situações vividas pelas crianças quando brincavam de supermercado, favoreceram especialmente a mobilização da dimensão motora, principalmente quanto aos movimentos finos de manipulação:

$$
\begin{aligned}
& \text { D: - Não está vendo DA, que esta caixa é pequena } \\
& \text { e não cabe no lugar da maior? Tome cuidado. D: - } \\
& \text { B, não é só ir jogando as caixas, uma em cima da } \\
& \text { outra, é preciso colocar certo, as maiores embaixo } \\
& \text { e as menores em cima. G: - Eu, B e J fizemos um } \\
& \text { prédio bem alto, com várias caixas. Agora vamos } \\
& \text { tentar transportar. }
\end{aligned}
$$

Observando o desenrolar das aulas, notamos o progresso em relação aos cuidados com os materiais utilizados para montar e fazer funcionar o supermercado. Cuidados que se referiam a inúmeras dimensões, mas que, para serem concretizados, solicitavam das crianças gestos precisos e bem coordenados.

Movimento, Porto Alegre, v. 14, n. 01, p. 111-134, janeiro/abril de 2008. 


\subsection{Progressos referentes à afetividade:}

é uma dimensão revestida, na escola, de uma severa blindagem, para que o sistema educacional possa ignorá-la enquanto cuida do pensamento lógico-matemático, até porque, de modo geral, conhecemos pouco a respeito dos afetos.

Numa certa aula, indagamos a MA porque ela estava caminhando de mãos dadas com MI: "MA: É porque nós estamos brincando de mãe e filha, que são muito amigas."

A situação traduz uma relação amistosa, de amizade, amor entre as duas crianças. Porém, na cena educacional, é importante a pergunta do professor. Ao fazer a pergunta, leva as crianças a tomarem uma posição de distanciamento da situação vivida, oportunizando a crítica, a compreensão, o lidar com tais sentimentos.

Em outra aula, registramos: "LA: Tio! Hoje vai ter aula de Educação Física? Professor: - Sim, vai. LA: Ôba! Sabe que eu adoro aula de Educação Física? É legal! E o senhor é bom e muito querido, sabia? Um dia o senhor me convida para ir à sua casa? Um dia..."

Freinet (2001) observava isso em suas aulas:

Não somos rigorosos sobre a forma da polidez. Essa criança vem em nossa direção, com pressa de nos participar uma descoberta feita a caminho ou com uma notícia a nos anunciar. Em sua pressa, ela se esquece de dizer bom dia; mas sua confiança acaso não é o mais delicado dos bons-dias? (FREINET, 2001, p. 77)

Havia um menino que, em sala de aula, criava inúmeras dificuldades. Chegava a recusar ficar em sala, gerando sérios problemas na escola. No supermercado, foi designado, pelas outras crianças, para coordenar as questões de dinheiro, controlar a gôndola de refrigerantes e trabalhar no caixa. Seu comportamento, nessa brincadeira, não destoava dos demais. A esse respeito, o aluno $\mathbf{E}$, afirmou: "Hoje nós colocamos o $\mathbf{L}$ para contar dinheiro, para ver se ele pára de provocar os outros. Na sala é terrível. E colocamos o

Movimento, Porto Alegre, v. 14, n. 01, p. 111-134, janeiro/abril de 2008. 
MA para ajudar no empacotamento das mercadorias, porque ele fica sempre sozinho."

Trata-se de um momento muito oportuno para o crescimento afetivo dessas crianças, para que aprendam a lidar com emoções e sentimentos. Segundo depoimento da professora de sala, naquele momento, os alunos estavam ajudando bastante dentro da sala e MA evoluía a olhos vistos, produzindo e fazendo alguns desenhos.

É possível que, hoje, seja tão importante educar a afetividade quanto o pensamento lógico-matemático. Sabemos como é difícil convencer os professores de que é possível ensinar a lidar com as emoções e educar sentimentos para que os alunos sejam amorosos, solidários e compassivos. Porém, nessa experiência das Oficinas do Jogo, a todo instante as crianças estavam colocando em seus jogos os sentimentos vividos no cotidiano.

\subsection{Progressos quanto às relações sociais.}

As crianças aprenderam a realizar trocas, a chegar a acordos, a agir cooperativamente. Com o passar do tempo, não se notavam, na brincadeira de supermercado, desavenças, acusações. As crianças obedeciam às filas para compras e pagamentos no supermercado e ninguém reclamava de ter sido burlado no troco. Uma das mães de crianças observou que a aula de Educação Física parecia unir mais as crianças, que elas não saíam da frente da porta da sala e sempre brincavam juntas. De fato, o jogo cativou muito aquelas crianças. Como afirmava Huizinga (1996, p.13): “O jogo lança sobre nós um feitiço: é "fascinante', 'cativante"”.

Registramos essa conversa entre as crianças: "L: Estas caixas nós não estamos usando, vamos dar para a turma do $\mathbf{P}$. B: Sim, não vamos usar mesmo."

Essas duas crianças, em entrevista posterior, confirmaram que uma das maiores lições que aprenderam nas Oficinas do Jogo foi dividir os materiais com os amigos, não discutir (brigar) com os colegas e ajudar os amigos que estavam em dificuldades.

Movimento, Porto Alegre, v. 14, n. 01, p. 111-134, janeiro/abril de 2008. 


\subsection{Progressos quanto à estética.}

PI, observando uma construção de torre com tampinhas de garrafa, feita pelo amigo G, exclama: “ Puxa! Que bonito! Está super legal! Até parece a torre de TV Cultura no Morro da Cruz. Sabe cara, o seu ainda é mais massa, todo coloridão, parece que tem muito sol, sabe, né, fim de tarde, reflexo, aquela luz alaranjada que fica parecendo raio, beleza total."

Sensibilidade à beleza que Paulo Freire (2003, p. 77) sempre destacou: "[...] parar e admirar o pôr do sol. É o que detém, perdido na contemplação da rapidez e elegância com que se movem as nuvens no fundo azul do céu. É o que emociona em face da obra de arte que me centra na boniteza".

Pergunto a $\mathbf{J}$ : "Por que a folha da árvore caiu?" E ele me responde: "A folha caiu de felicidade. Ela quer nos mostrar que é feliz, pular, dançar, e aí caiu. Ela quer ser feliz, ela queria ser como nós."

Brougère (1998, p. 90) disse que: "O poeta faz como a criança que joga; cria um mundo imaginário que leva muito a sério, isto é, que dota de grandes qualidades de afetos, distinguindo-o claramente da realidade".

G está empenhado numa construção com algumas tampas de garrafa: "Tio, olha o que eu fiz!", ao que $\mathbf{P}$, ao seu lado, exclama: "Pô meu, isso é uma obra de arte!"

Então eu pergunto a $\mathbf{P}$ o que é uma obra de arte: "P: Obra de arte é isso aí ó!" Fazendo beicinho e apontando com o indicador para o trabalho do colega.

Durante uma de nossas aulas, a diretora da escola apareceu e viu a construção do supermercado. Não se conteve e falou para as crianças: "Nossa, que supermercado lindo! Nunca vi um supermercado tão alegre e chique como o de vocês, e quantas paredes diferentes!"

As crianças responderam: "A senhora vai ver amanhã, nós vamos fazer um maior e mais bonito, se não voltar para uma visita,

Movimento, Porto Alegre, v. 14, n. 01, p. 111-134, janeiro/abril de 2008. 
vai perder a belezura. Não é só a parede, as prateleiras também são modernas e bem coloridas, lindonas."

Podemos dizer que a beleza pode ser ensinada. Os exemplos em nosso trabalho são incontáveis. Não falamos de uma aprendizagem nos moldes tradicionais, quando, na escola tradicional, as coisas são apenas transmitidas, mas num outro conceito de escola.

\subsection{Progressos quanto ao pensamento lógico-matemático}

A: "Vamos enfileirar uma tampinha ao lado da outra. P: Vamos colocar umas cem. A: Tudo de uma cor? P: Não, a gente mistura. Ó A, não esqueça de contar, para ficar certinho, hein!"

A afirma na entrevista que aprendeu no jogo de supermercado a somar mais rápido, a vender, dar o troco e manter boas relações com os demais colegas.

Nas Oficinas do Jogo, os alunos, a exemplo de $\mathbf{P}$ e $\mathbf{A}$, organizam seu pensamento dentro de um contexto. Os cálculos que realizam inserem-se no contexto da brincadeira de supermercado, portanto, fazem sentido para eles, têm significado. Vejam o que diz uma aluna, durante a brincadeira:

J: - Tio, olha o que eu acabei de descobrir: tem garrafas pequenas pesadas; outras grandes de refrigerantes, leves, umas mais cheias que as outras, umas maiores e outras menores, uma bem grandona, umas mais cheias que outras. É para a gente aprender a calcular o peso, não é? O senhor é sabido, hein! Posso colocar nas prateleiras?

Há, nessa manifestação, indícios de tomada de consciência. Certamente, antes de chegar à afirmação que transcrevemos, a aluna pensou bastante e concluiu corretamente. Quanto ela deve ter explorado o material e refletido sobre suas ações para chegar a tal conclusão! Não foi o preciso o professor dar a informação, ela deduziu. Em sua entrevista, posteriormente, $\mathbf{J}$ mencionou que através dos jogos aprendeu a calcular e organizar. Num outro momento, ocorreu este dialogo:

Movimento, Porto Alegre, v. 14, n. 01, p. 111-134, janeiro/abril de 2008. 
Professor: O que você está fazendo? J: Eu estou medindo os pauzinhos (bastões), depois vou fazer uma escada. Professor: Como você vai fazer a escada? J: Assim tio: eu coloco o bastão no chão, e vou colocando do pequeno para o grande. Professor: Ah! Entendi. Então faça que eu quero ver. J: - Eu vou mostrar para o senhor, do jeito que eu vi as roupas lá da loja, tudo enfileiradinhas. Bem bonito e arrumado.

Sem muita pressa ela vai observando, tentando, trocando os bastões, até atingir seu objetivo.

Foram tantas as aulas, e tantos os exemplos colhidos, que seria longo demais descrevê-los aqui. Além dessas expressões colhidas durante as várias aulas, no final do ano letivo, pedimos às crianças que escrevessem a respeito das aulas. Todas se mostraram capazes de escrever seus depoimentos, embora, em muitos casos, ainda com certo embaraço. Trechos dos depoimentos escritos:

\footnotetext{
[...] eu aprendi continha e ajudar os amigos eu divido as coisas eu gosto do professor [...] eu aprendi a respeitar os amigo e divido os brinquedos os amigos[...]. Eu sou inventor do supermercado Havon. A minha especialidade é brincar e inventar material. [...] Eu aprendi ter amigos. [...] Eu adoro brincar com a secretaria. [...] Eu fico na caixa. [...] Eu amo o tio Ciro na escola como ele fosse meu pai.
}

Vale destacar que, no início do ano letivo, muitas delas eram incapazes de ler e escrever. Não podemos afirmar que foi por causa das Oficinas do Jogo que elas aprenderam a ler e escrever, esse é apenas mais um dado que confirma o progresso obtido pelas crianças, do ponto de vista intelectual. Mas podemos supor, nessa aprendizagem, a influência das Oficinas do Jogo, pois verificamos em levantamento anterior (FEIJÓ, 2005), que é comum, entre escolares de bairros economicamente empobrecidos, não aprenderem a ler e a escrever nas primeiras séries do Ensino Fundamental.

Na educação tradicional, os problemas são dados pela escola, assim como as soluções para eles. Nas Oficinas do Jogo, pelos

Movimento, Porto Alegre, v. 14, n. 01, p. 111-134, janeiro/abril de 2008. 
exemplos vistos, os temas desenvolvidos pelas crianças geraram os problemas. As crianças buscaram soluções porque elas eram necessárias para dar prosseguimento à brincadeira. Como vimos, elas compararam, fizeram correspondências, reverteram, classificaram, seriaram, conservaram, provocadas pela enorme diversidade de situações suscitadas pelos jogos. Ora, e de que matéria é constituída o pensamento lógico-matemático, senão dessas noções básicas de pensamento?

\section{Considerações Finals}

Considerando os índices de reprovação escolar na rede pública de ensino divulgados pelas secretarias de educação, ainda preocupantes, percebemos que nas escolas localizadas em bairros desfavorecidos economicamente esses índices são maiores que nos bairros economicamente favorecidos. E a escola pesquisada convive com esta realidade, pois recebe com freqüência um número significativo de alunos oriundos de comunidades empobrecidas, que residem nas proximidades da unidade de ensino.

Uma das exigências da escola é que a criança aprenda os conteúdos escolares, ou seja, o saber formal, cientificizado. Sabemos também que a criança vem de um ambiente lúdico e informal (quando ela tem oportunidade de criar seu ambiente de criança). Porém, na maioria das vezes, a escola não oferece a possibilidade de intermediação entre o conhecimento informal adquirido no universo cultural da criança e o conhecimento formal da escola.

Não existindo a ponte que faça a aproximação entre a realidade cultural vivida pela criança e as obrigações rotineiras da escola, ela enfrentará dificuldades para superar os obstáculos enfrentados, levando à reprovação ou sendo aprovada por complacência, sem estar alfabetizada. E não se trata apenas de um problema localizado na escola. A falta de instrumentos para assimilar os conteúdos escolares, assim como a falta de educação em outros planos que não os da escola tradicional, repercutirão nas tentativas de emancipação social dessas crianças no futuro.

Movimento, Porto Alegre, v. 14, n. 01, p. 111-134, janeiro/abril de 2008. 
Pensando em diminuir a distância entre a rua e a escola (isto é, entre o cotidiano da criança e as atividades formais escolares), e, rompendo com a tradicional aula de Educação Física, implantamos as Oficinas do Jogo, um conjunto de materiais pedagógicos, metodologias e jogos que constituem ambientes adequados para educar de um outro jeito, permitindo que a criança freqüente a escola sem deixar de ser criança. Romper com a tradição da escola antiga, entre outras coisas; significa poder produzir um ambiente lúdico, típico da infância, significa ensinar a pensar, ensinar a se expressar, a lidar com sentimentos, a viver coletivamente, a articular as individualidades para compor grupos.

A escola pesquisada, no ambiente das Oficinas do Jogo, deixou a cargo dos próprios alunos gerarem os temas de jogos. Em outra pesquisa já realizada por nós anteriormente, uma professora, nas Oficinas do Jogo, sugere, ela mesma, os temas para as crianças. Queríamos saber se, não recebendo sugestões de temas, elas poderiam gerá-los e desenvolvê-los por conta própria. E se tais temas, gerados por elas, produziriam resultados semelhantes ao da outra pesquisa.

Diversos temas foram criados pelos alunos. Em contato com o material reciclado elas se entregaram intensamente ao jogo, sempre coletivo, de onde brotaram motivos diversos para brincar. O mais freqüente de todos, sem dúvida, foi o do Supermercado. Durante meses as crianças realizaram essa brincadeira, que parecia não ter fim. A cada aula, novos ingredientes eram acrescentados. E tudo aquilo que vimos acontecer na pesquisa que sugeria previamente os temas para os alunos (a anterior, já finalizada), neste caso também aconteceu, como pudemos ver na interpretação dos dados realizada. O Supermercado nasceu, cresceu e se expandiu entre as crianças das duas turmas que viveram estas experiências das Oficinas do Jogo. Mereceu delas batismos diferentes e tornou-se a maior atração das Oficinas do Jogo durante os trabalhos de pesquisa.

As crianças saíram a campo. Não podiam organizar um bom supermercado sem conhecer o que se passava no interior de um deles de verdade. A fantasia tem a configuração de algo real, mas

Movimento, Porto Alegre, v. 14, n. 01, p. 111-134, janeiro/abril de 2008. 
integra o invisível. O estabelecimento comercial de mentirinha tinha, para elas, que ser muito parecido com o real, mas, lá dentro, durante os jogos, as experiências de vida de cada um iam sendo depositadas e brincadas (outra maneira de viver cada coisa). Elas pesquisaram mercadorias, preços, qualidade, organização. Tiveram que montar departamentos, lidar com dinheiro, fazer cálculos e escrever. Aquilo que, habitualmente, só é típico da disciplina Educação Física, passou a integrar conhecimentos de diversas áreas. Acabou gerando um tema que as obrigava a pensar, logo, isso repercutiu em outras atividades que exigiam o pensamento lógico-matemático, como as disciplinas de sala de aula. Lidar com um supermercado exige falar bem e escrever, o que contribuiu com os conteúdos de português. O material reciclado e os arranjos do estabelecimento comercial, entre outras brincadeiras, produziram um ambiente riquíssimo em beleza. Mesmo não sendo nossa intenção lidar com educação artística, os sintomas de enriquecimento do sentido estético das crianças foram muito evidentes.

O professor da disciplina, que era também o pesquisador, esteve o tempo todo presente, intermediando as relações entre as crianças e entre elas e os jogos. Sua presença fez parte dos jogos. Sua pesquisa o pesquisou. Os conflitos surgiam e o professor estava lá, pronto para intermediá-los. Como se viu nas análises, os alunos sempre chegavam a acordos, pois a motivação do jogo era forte e eles queriam prosseguir na brincadeira. O professor nunca impunha uma regra, ela tinha que ser construída por acordo entre os alunos.

As professoras dessas crianças foram unânimes em reconhecer os avanços conseguidos por elas durante o período em que observamos suas atividades nas Oficinas dos Jogos. Entre outras coisas, aprenderam a ler e a escrever. Não que isso não pudesse ser conseguido sem as Oficinas. Claro que as professoras poderiam chegar a esse resultado, mas o fato é que, em escolas de bairros economicamente empobrecidos, é cada vez mais freqüente a criança avançar para as séries seguintes sem dominar a escrita, a leitura e as operações elementares. Quando nosso trabalho começou, pouquíssimas sabiam ler e escrever alguma coisa. Ao final, todas

Movimento, Porto Alegre, v. 14, n. 01, p. 111-134, janeiro/abril de 2008. 
demonstraram progresso nesses quesitos Para crianças moradoras desses bairros, agredidas diariamente pela violência urbana varrida para a periferia, incorporar instrumentos como leitura e escrita é fundamental. É difícil pensar em emancipação quando pelo menos isso não é aprendido. Esse foi um dos resultados maiores do trabalho com as Oficinas do Jogo: contribuir para aumentar o poder de assimilação dos conteúdos escolares. E quanto ao resto, isto é, a educação em outros planos? Aprender a pensar, por exemplo, não repercute só na matemática ou no português; é para toda a vida. Assim como aprender a viver socialmente, a construir regras, a apreciar a beleza, a lidar com sentimentos, a conhecer o próprio corpo, entre outros elementos indispensáveis para uma vida autônoma. Para muitas crianças, não se trata só de passar de ano, mas de escapar da miséria, mas de adquirir o direito à vida.

Movimento, Porto Alegre, v. 14, n. 01, p. 111-134, janeiro/abril de 2008. 
Playing and Producing: the workshops of game as an educational proposal in the initial years of Elementary School.

Resume: Taking into account the historical difficulties of the Brazilian children who attend the public schools to learn the basic contents, we suggest a pedagogical practice with greater means to improve the quality of this learning. Starting from the idea that the ludic constitute a favorable environment to the learning process, the central goal of this study was to verify the potential of the Workshops of Game as a pedagogical practice that is able to produce repercussions in other school learning processes, as well as to produce learning processes in other levels not anticipated by the traditional school. The Workshops of Game are a pedagogical practice situated within the Physical Education discipline (gym class), in which in playing, the children learn the basis of knowledge (thinking, body motor function, sociability, morality, affectivity, etc.), and do it in a way as to have repercussions in other school disciplines. The investigation method adopted was the Research-Action.

Keywords: Physical Education. Play and playting. Education, primary and secondary. Pedagogy

Fabrincando: Los Talleres de Juegos como propuesta educacional en los años iniciales de la Ensenãnza Fundamental.

Resumen: Considerando las dificultades de los niños brasileños que frecuentan las escuelas publicas para aprender los contenidos básicos, sugerimos una practica pedagógica que visa mejorar la calidad de esa aprendizaje. Partiendo de la idea la actividad deportiva constituye un ambiente favorable a la aprendizaje, el objetivo central de eso estudio fue verificar el potencial de los "Talleres de Juego" como practica pedagógica. Se espera que esa practica sea capaz de repercutir en otras aprendizajes escolares, así como inducir aprendizajes en otros planos no previstos por la escuela tradicional. Los "Talleres de Juegos" son una practica pedagógica localizada en la disciplina de Educación Física, en la cual los niños, jugando aprenden las bases del conocimiento (pensamiento, motricidad, sociabilidad, moralidad, afectividad, etc.) lo haciendo de modo a repercutir en otras disciplinas escolares. El método de investigación adoptado fue el de pesquisa-acción. Palabras-clave: Educación Física. Juego e implementos de juego. Educación primária e secundaria. Pedagogia.

Movimento, Porto Alegre, v. 14, n. 01, p. 111-134, janeiro/abril de 2008. 


\section{REFERÊNCIAS}

ATLAN, Henri. Com razão ou sem ela. Lisboa: Instituto Piaget, 1994.

BETTI, Mauro. "Imagens em ação": uma pesquisa-ação sobre o uso de matérias televisivas em programas de educação. Movimento, Porto Alegre, v.12, n. 2, p. 95-120, maio/ago. de 2006.

BROUGĖRE, Gilles. Jogo e educação. Porto Alegre: Artes Médicas, 1998.

DUSSEL, Henrique. Ética da Libertação: na idade da globalização e da exclusão. Petrópolis: Vozes, 2000.

FEIJÓ, Atagy Terezinha Maciel. Oficinas do jogo: uma abordagem pedagógica transdisciplinar nas séries iniciais do ensino fundamental. 2005. 144 f. Dissertação (Mestrado em Educação Física) - CEFID -Universidade do Estado de Santa Catarina. Florianópolis, SC. 2005.

FRANCO, Maria Amélia Santoro. Pedagogia da pesquisa-ação. Disponível em <http://scielo.br.php?=S1517-97022005000300011\&script=sci_arttext. $>$ Acesso em: 12 abr. 2007.

FREINET, Célestin. Para uma escola do povo. São Paulo: Martins Fontes, 2001.

FREIRE, João Batista. Educação de corpo inteiro: teoria e prática da educação física. São Paulo: Scipione, 1989.

FREIRE, João Batista. O jogo: entre o riso e o choro. Campinas: Autores Associados, 2002.

FREIRE, João Batista; SCAGLIA, A. José. Educação como prática corporal. São Paulo: Scipione. 2003.

FREIRE, Paulo. Pedagogia do oprimido. 40. ed. Rio de Janeiro: Paz e Terra, 2005b. .

À sombra desta mangueira. São Paulo: Olho d’Água, 2003.

Professora sim, tia não: cartas a quem ousa ensinar. São Paulo: Olho d'Água, 2005a.

GEHLEN, Arnold. El hombre. Salamanca: Sigueme, 1987.

HUIZINGA, Johan. Homo Ludens. São Paulo: Perspectiva, 1996.

NEIRA, Marcos Garcia; NUNES, Mário Luiz Ferrari. Pedagogia da cultura corporal: crítica e alternativas. São Paulo: Phorte, 2006.

NETO, Luis Sanches et al. Sistematização de conteúdos temáticos na educação física escolar: uma proposta de professores-pesquisadores. In: FONTOURA, P.

Movimento, Porto Alegre, v. 14, n. 01, p. 111-134, janeiro/abril de 2008. 
(org). Pesquisa em Educação Física. Jundiaí: Fontoura Editora, 2006. (Coleção Pesquisa em Educação Física, 4)

ORTEGA Y GASSET, José. Em torno a Galileu: esquema das crises. Petrópolis, RJ: Vozes, 1989.

PIAGET, Jean. A construção do real na criança. Rio de Janeiro: Zahar, 1979.

A formação do símbolo na criança: imitação, jogo e sonho. Imagem e representação. Rio de Janeiro: Zahar, 1978.

SAEB. Dificuldade de aprendizado é maior a cada ano. O Estado de São Paulo. São Paulo, 27 abr. 2003. Setor Educação, Caderno A.

SANTA CATARINA. SECRETARIA DE ESTADO DA EDUCAÇÃO E DO DESPORTO. Proposta Curricular de Santa Catarina: Educação Infantil, Ensino Fundamental e Médio: Formação docente para educação infantil e séries iniciais. Florianópolis: COGEN, 1998.

SÉRGIO, Manuel. Para um novo paradigma do saber e... do ser. Coimbra: Ariadne, 2005.

SOARES, Carmen Lucia et al.. Metodologia do ensino de Educação Física. São Paulo: Cortez, 1993.

THIOLLENT, MICHEL. Metodologia da pesquisa-ação. São Paulo: Cortez, 2004.

Movimento, Porto Alegre, v. 14, n. 01, p. 111-134, janeiro/abril de 2008. 